\title{
Characterisation of lightning flashes from changing electric field measurements in Johannesburg, South Africa
}

\author{
J. D. Tasman, C. Schumann, \\ H. G. P. Hunt, H. G. Fensham, \\ K. J. Nixon \\ School of Electrical and Information \\ Engineering \\ University of the Witwatersrand \\ Johannesburg, South Africa \\ jesstasman@gmail.com
}

\author{
M. M. F. Saba \\ Atmospheric Electricity Group \\ Brazilian National Institute for Space \\ Research \\ São José dos Campos, Brazil \\ marcelo.saba@inpe.br
}

\author{
T. A. Warner \\ ZT Research \\ Rapid City, South Dakota, USA \\ tom.warner@ztresearch.com
}

\begin{abstract}
Presented are results obtained from changing electric field measurements and high-speed video analysis on lightning flashes over Johannesburg, South Africa. A flat-plate antenna and integrator were used to record changing electric fields and the high-speed footage was recorded using Phantom $v 310$ and $v 7.1(15,000$ fps and 5,000 fps respectively) cameras. A total of 34 negative strokes and 3 positive strokes were analysed. The recorded negative strokes presented an average peak intensity of $8.0 \mathrm{~V} / \mathrm{m}, 0-100 \%$ rise time of $3.3 \mu \mathrm{s}, 10$ $90 \%$ rise time of $1.8 \mu \mathrm{s}$ and pulse duration of $6.4 \mu \mathrm{s}$. The positive strokes presented an average peak intensity of $36.7 \mathrm{~V} / \mathrm{m}, 0-100 \%$ rise time of $22.9 \mu \mathrm{s}, 10-90 \%$ rise time of $7.4 \mu \mathrm{s}$ and pulse duration of $33.4 \mu \mathrm{s}$. The average continuing current durations, determined using high-speed videos, was $6.3 \mathrm{~ms}$ for the negative strokes and $81.5 \mathrm{~ms}$ for the positive strokes.
\end{abstract}

Keywords—changing E-field; flat-plate antenna; high-speed video; rise time

\section{INTRODUCTION}

Previous studies have been performed using changing electric field (E-field) measurements to characterise and record data from cloud-to-ground (CG) lightning flashes. These include studies performed in Brazil, Austria, Malaysia and Florida (USA), among others [1-4]. The common parameters recorded from the changing electric field profiles measured in these studies include rise times, intensities and durations. These parameters correspond to the attachment of a leader and the magnitude and duration of the current impulse. If the strike-point is too close to the measurement device, the electronics could be driven into saturation and an accurate profile may not be obtainable. The ideal setup would have sensors installed at a range of distances. The presence of a near and far E-field measurement sensor ensures that all recorded strokes can be analysed.

High-speed videos and changing electric field measurements are two accurate ways in which lightning flashes can be characterised and analysed. From 10 February 2017 to 6 February 2018, both methods were applied in assessing lightning flashes that occurred in Johannesburg,
South Africa. For the changing electric field data to be viewed, the E-field files were analysed using the Dataviewer 1.4 software.

A flat-plate antenna is set up to perform changing electric field measurements and is detailed in Section II. The highspeed video and changing E-field measurement studies are presented in Section III and IV. These sections include a detailed methodology on the extraction of the aforementioned parameters from the recorded measurements. Comparisons between previous studies and the results from this study are presented in Section V.

\section{CHANGING ELECTRIC FIELD MEASUREMENTS}

Measuring a change in the electric field between a thundercloud and the ground is a highly effective way of characterising lightning flashes. In this study, a flat-plate antenna was used to perform these changing electric field measurements. Using the assumption of an infinite ground plane, justified by Cooray [5], the flat-plate antenna measures a change in the vertical electric field by using a capacitive antenna. The output signal from the antenna is then integrated and amplified, which allows for a waveform to be resolved that is proportional to the time derivative of the measured electric field.

A flat-plate antenna and integrator system was installed at coordinates $26.19134^{\circ} \mathrm{S}, 28.02712^{\circ} \mathrm{E}$, on the roof of a four-story building in Johannesburg, South Africa. The integrator has a decay time-constant of $0.47 \mathrm{~s}$ and operates at a bandwidth between $300 \mathrm{~Hz}$ and $1.5 \mathrm{MHz}$. The measurement system comprises of a 12-bit, $5 \mathrm{MS} / \mathrm{s}$ PCI N6110 National Instruments digitiser, which allows for continuous recording. An external antenna and a Meinberg PCI-170GPS board is integrated into the system to ensure accurate time stamping of recordings. This allows for time correlation with other measurement equipment, such as highspeed cameras. The process that the changing E-field measurement equipment follows is presented in Fig. 1.

The flat-plate antenna set-up is shown in Fig. 2. A PV panel is utilised to ensure the battery used to power the integrator is always sufficiently charged. 


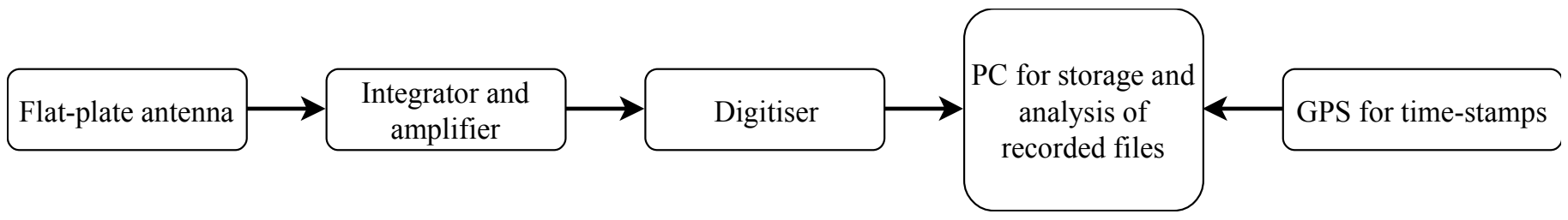

Fig. 1. High-level flow diagram of changing electric field measurement process

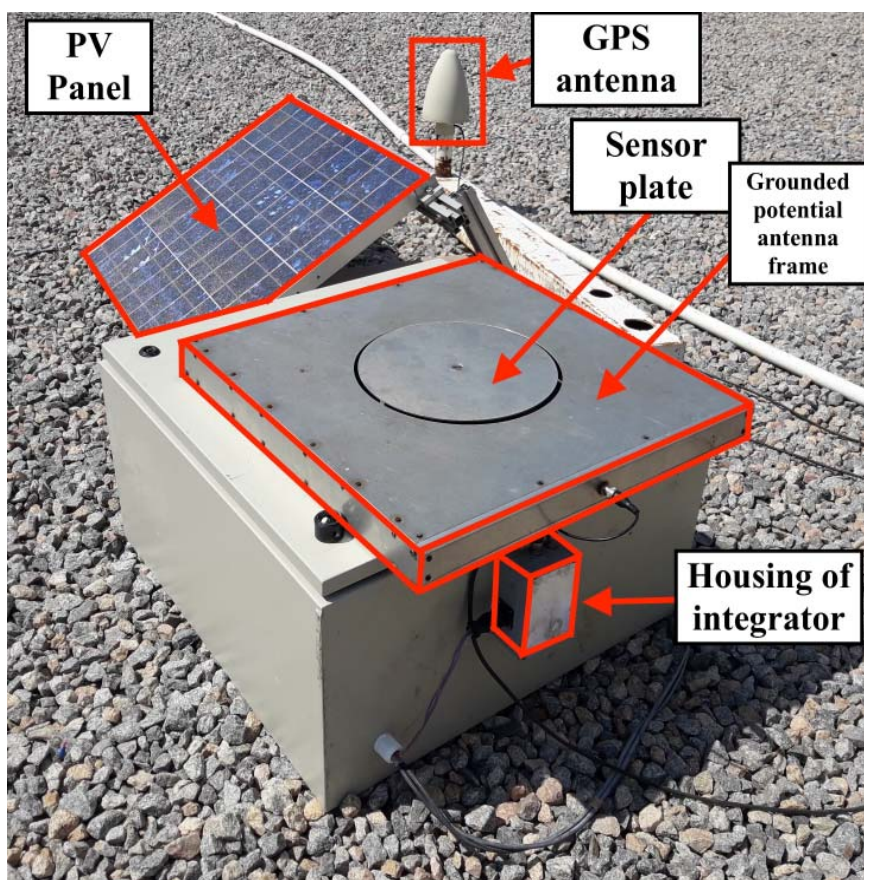

Fig. 2. Flat-plate antenna set-up

\section{HIGH-SPEED VIDEO CAMERAS}

The high-speed cameras used in this study are the Phantom v310 (15,000 fps, exposure time $58 \mu \mathrm{s})$ and the Phantom v7.1 (5,000 fps, exposure time $990 \mu \mathrm{s})$. The difference in frame rate and exposure time of each camera allows for the footage to be compared and ultimately, more accurate characterisation of lightning flashes.

The cameras are installed at coordinates $26.1614^{\circ} \mathrm{S}$, $27.957^{\circ} \mathrm{E}$. This is approximately $8 \mathrm{~km}$ Northwest of central Johannesburg. The field of view of the cameras relative to the Brixton and Hillbrow towers and the changing E-field measurement set-up is shown in Fig. 3.

\section{ANALYSIS}

The following section presents an analysis of the changing electric field data. This includes a detailed methodology on the characterisation process of the recorded changing E-field data and the overall results. Previous studies were consulted to ensure the analysis procedure produced comparable results $[6-8]$.

\section{A. Data}

The changing electric field data consists of lightning flashes occurring between 10 February 2017 and 6 February 2018. A sample waveform of a negative flash registered by the flat-plate antenna system is presented in Fig. 4. Peak intensity magnitudes, rise times $(0-100 \%$ and

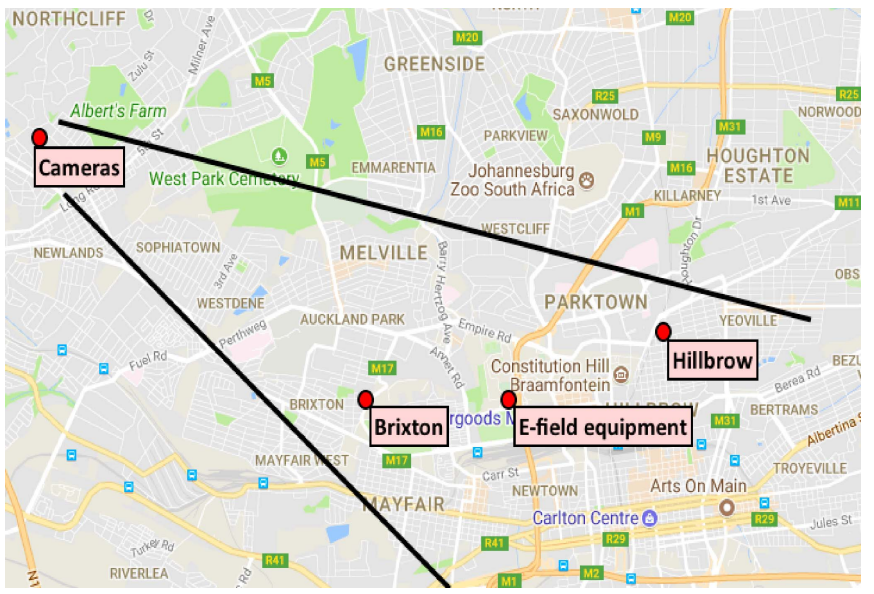

Fig. 3. Map illustrating field of view of high-speed cameras (developed using Google Maps software)

$10-90 \%$ ) and pulse durations were obtained from the waveforms.

In this study, the distance from the sensor to the strikepoint of the flashes ranged from $5.7 \mathrm{~km}$ to $28.2 \mathrm{~km}$. In this distance range, the radiation field component of the propagated electromagnetic field is prominent. Distances were claculated using the strike-point coordinates obtained from the South African Lightning Detection Network (SALDN). The recorded intensity of the change in the electric field is dependent on the distance the strike-point was relative to the flat-plate antenna. To allow for this parameter to be compared objectively with other studies, the recorded peak intensities were normalised to $100 \mathrm{~km}$.

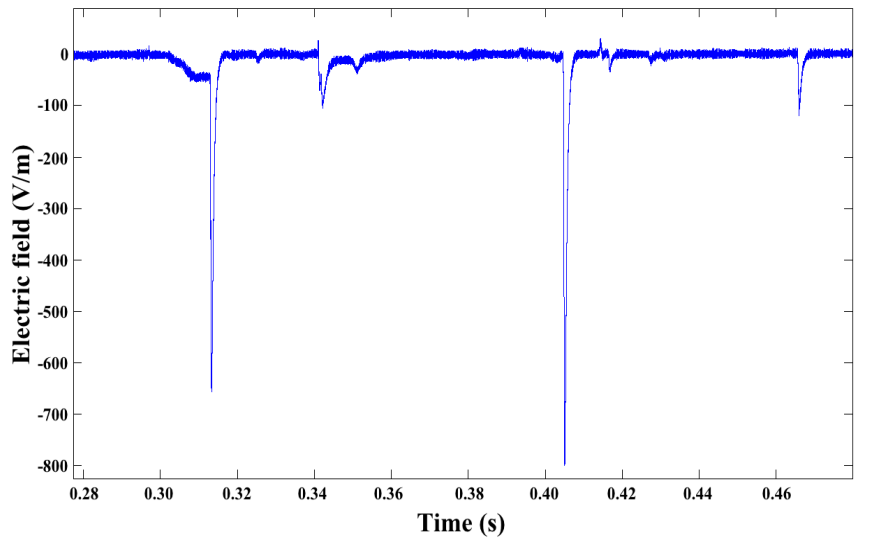

Fig. 4. Sample of a negative flash waveform

\section{B. Methodology}

The waveform of a negative stroke is shown in Fig. 5. The slow front (SF) and fast transition (FT) phases 
associated with this stroke is discussed by Tran and Rakov [9] and illustrated on Fig. 5. With reference to the time (T) and intensity (i) parameters used in this section, the points indicated in Fig. 5 are defined by the following parameters:

- $\mathrm{A}:\left(\mathrm{T}_{0}, \mathrm{i}_{0}\right)$

- $\quad$ B: $\left(\mathrm{T}_{100}, \mathrm{i}_{100}\right)$

- $\quad \mathrm{C}:\left(\mathrm{T}_{\text {end }}, \mathrm{i}_{50}\right)$

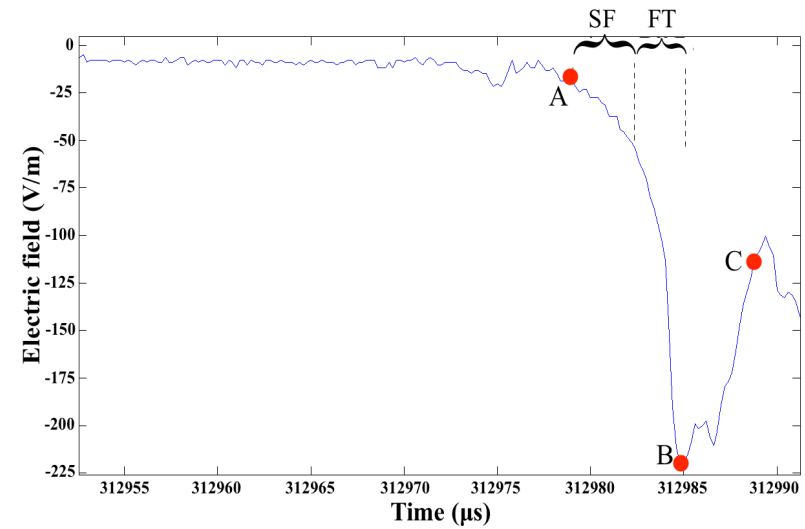

Fig. 5. Slow front (SF) and fast transition (FT) of a changing electric field waveform of a negative return stroke

Determination of changing E-field parameters:

1) Changing E-field intensity

- Take point $\mathrm{A}$ as the intensity where the waveform gradient begins its decay to infinity.

- Take point $\mathrm{B}$ as the intensity at the peak of the stroke.

- $\mathrm{i}_{\max }=\mathrm{i}_{100}-\mathrm{i}_{0}$

2) Normalised peak intensity

- Determine distance between strike-point and changing E-field measurement device using SALDN coordinates of strike-point.

- Normalise peak intensity to $100 \mathrm{~km}$.

3) $0 \%-100 \%$ rise time $\left(T_{0-100}\right)$

- $\mathrm{T}_{0}$ is the time at $\mathrm{i}_{0}$

- $\mathrm{T}_{100}$ is the time at $\mathrm{i}_{100}$

- $\mathrm{T}_{0-100}=\mathrm{T}_{100}-\mathrm{T}_{0}$

4) $10 \%-90 \%$ rise time $\left(T_{10-90}\right)$

- $\mathrm{T}_{10}$ is the time corresponding to $\mathrm{i}_{10}$

$$
\text { ○ } \mathrm{i}_{10}=\mathrm{i}_{0}+0.1\left(\mathrm{i}_{100}-\mathrm{i}_{0}\right)
$$

- $\mathrm{T}_{90}$ is the time corresponding to $\mathrm{i}_{90}$

$$
\text { ○ } \mathrm{i}_{90}=\mathrm{i}_{0}+0.9\left(\mathrm{i}_{100}-\mathrm{i}_{0}\right)
$$

- $\mathrm{T}_{10-90}=\mathrm{T}_{90}-\mathrm{T}_{10}$
5) Pulse duration ( $\left.T_{\text {duration }}\right)$

- $\mathrm{T}_{\text {end }}$ at point $\mathrm{C}$ on Fig. 5 is the time taken for the intensity to return to $50 \%$ of $i_{100}$ from point $A\left(T_{0}\right)$.

- $\mathrm{T}_{\text {duration }}=\mathrm{T}_{\text {end }}-\mathrm{T}_{0}$

6) Polarity

- Classified as positive if $\mathrm{i}_{100}>\mathrm{i}_{0}$

- Classified as negative if $\mathrm{i}_{100}<\mathrm{i}_{0}$

\section{Results}

From a total of 18 recorded flashes, 15 were classified as negative $C G$ and 3 as positive $C G$. From the 15 negative flashes, a total of 34 strokes were observed and only two consisted of more than 3 strokes (6 strokes and 9 strokes). All three positive flashes consisted of only one stroke. The arithmetic means (AM) and geometric means (GM) of the data obtained from the positive strokes and negative strokes are presented in Table I and Table II, respectively.

TABLE I. POSITIVE STROKES (3 SAMPLES)

\begin{tabular}{|cccc|}
\hline Parameter & AM & GM & Unit \\
\hline Normalised peak intensity & 40.5 & 36.7 & $\mathrm{~V} / \mathrm{m}$ \\
\hline $\mathrm{T}_{0-100}$ & 23.7 & 22.9 & $\mu \mathrm{s}$ \\
\hline $\mathrm{T}_{10-90}$ & 7.8 & 7.4 & $\mu \mathrm{s}$ \\
\hline $\mathrm{T}_{\text {duration }}$ & 34.5 & 33.4 & $\mu \mathrm{s}$ \\
\hline
\end{tabular}

\begin{tabular}{|c|c|c|c|c|c|}
\hline & Samples & Parameter & AM & GM & Unit \\
\hline \multirow[t]{4}{*}{$1^{\text {st }} \mathrm{RS}$} & \multirow{4}{*}{12} & Normalised peak intensity & 9.4 & 8.6 & $\mathrm{~V} / \mathrm{m}$ \\
\hline & & $\mathrm{T}_{0-100}$ & 4.6 & 4.5 & $\mu \mathrm{s}$ \\
\hline & & $\mathrm{T}_{10-90}$ & 2.8 & 2.5 & $\mu \mathrm{s}$ \\
\hline & & $\mathrm{T}_{\text {duration }}$ & 9.3 & 8.5 & $\mu \mathrm{s}$ \\
\hline \multirow[t]{4}{*}{$2^{\text {nd }} \mathrm{RS}$} & \multirow{4}{*}{9} & Normalised peak intensity & 7.5 & 6.3 & $\mathrm{~V} / \mathrm{m}$ \\
\hline & & $\mathrm{T}_{0-100}$ & 4.0 & 3.5 & $\mu \mathrm{s}$ \\
\hline & & $\mathrm{T}_{10-90}$ & 2.6 & 2.3 & $\mu \mathrm{s}$ \\
\hline & & $\mathrm{T}_{\text {duration }}$ & 5.8 & 5.3 & $\mu \mathrm{s}$ \\
\hline \multirow[t]{4}{*}{$3^{\text {rd }} \mathrm{RS}$} & \multirow{4}{*}{5} & Normalised peak intensity & 8.1 & 7.7 & $\mathrm{~V} / \mathrm{m}$ \\
\hline & & $\mathrm{T}_{0-100}$ & 2.4 & 2.3 & $\mu \mathrm{s}$ \\
\hline & & $\mathrm{T}_{10-90}$ & 1.0 & 0.9 & $\mu \mathrm{s}$ \\
\hline & & $\mathrm{T}_{\text {duration }}$ & 7.0 & 6.4 & $\mu \mathrm{s}$ \\
\hline \multirow[t]{4}{*}{ All } & \multirow{4}{*}{34} & Normalised peak intensity & 9.5 & 8.0 & $\mathrm{~V} / \mathrm{m}$ \\
\hline & & $\mathrm{T}_{0-100}$ & 3.9 & 3.3 & $\mu \mathrm{s}$ \\
\hline & & $\mathrm{T}_{10-90}$ & 2.2 & 1.8 & $\mu \mathrm{s}$ \\
\hline & & $\mathrm{T}_{\text {duration }}$ & 7.4 & 6.4 & $\mu \mathrm{s}$ \\
\hline
\end{tabular}

TABLE II. NEGATIVE STROKES 


\section{DISCUSSION}

The results of the changing E-field measurements are discussed below and are compared with other studies. The durations measured from the changing electric field waveforms correspond to the pulse duration of the impulse phase of the lightning flash. The duration parameter attained from the high-speed videos represents the duration of the continuing current phase of the lightning flash.

\section{A. Changing electric field}

The Geometric mean (GM) of changing E-field peak intensities, normalised to $100 \mathrm{~km}$, for South Africa and Austria are provided in Table III. The Austrian data set used is made up of 31 return strokes. The integrator used for the flat-plate antenna in the Austrian study has a decay timeconstant of $0.5 \mathrm{~s}$ resulting in a similar bandwidth to the equipment used in this study, hence, ensuring comparable peak intensities.

TABLE III. GEOMETRIC MEAN OF NORMALISED CHANGING ELECTRIC FIELD INTENSITIES

\begin{tabular}{|c|c|c|c|}
\hline RS & $\mathbf{S A}$ & Austria [1] & Units \\
\hline All & $9.5^{*}$ & 8.6 & $\mathrm{~V} / \mathrm{m}$ \\
\hline
\end{tabular}

The Austrian data used in Table III lists a 0-100\% rise time of $7.4 \mu \mathrm{s}(\mathrm{GM})$ for all return strokes. For comparison, the GM for the same parameter from the data obtained in this study is $3.3 \mu \mathrm{s}$. A comparison of $0-100 \%$ and $10-90 \%$ rise times with studies conducted in Malaysia and Florida is presented in Table IV. A possible reason for the discrepancies in these rise-times could be due to the measurement equipment operating in different bandwidths.

TABLE IV. GEOMETRIC MEANS OF RISE TIMES FOR NEGATIVE FIRST RETURN STROKES

\begin{tabular}{|c|cccc|}
\hline RS & \% & SA & Malaysia [3] & Florida [2] \\
\hline $1^{\mathrm{st}}$ & $0-100$ & $4.5 \mu \mathrm{s}$ & $9.1 \mu \mathrm{s}$ & $6.5 \mu \mathrm{s}$ \\
& $10-90$ & $2.5 \mu \mathrm{s}$ & $5.0 \mu \mathrm{s}$ & $3.6 \mu \mathrm{s}$ \\
\hline
\end{tabular}

The data obtained from the positive flashes is compared with other studies and presented in Table V. The data collected in this study along with the study performed by Schumann, et al. [4] are tabulated in bold text as the antenna and integrator used were the same. This means the frequency content in both measurements are similar and, therefore, allow for accurate rise time comparisons. With the flat-plate antenna being placed on the roof of a building, a significant local, vertical electric field enhancement occurs. This effect will be accounted for by determining a scalar factor that will normalise the results.

\section{B. High-speed video correlation}

A set of data was compiled from high-speed video footage of all flashes corresponding to those recorded by the changing electric field measurement system. From these recordings, the luminosity persistence in the lightning channel after attachment had been made was used as an indicator for continuing current duration. A statistical summary of the continuing current durations for both negative and positive flashes is presented in Table VI. From the videos, the end of the continuing current was determined by when the channel disappeared. Visibility of the channel can vary based on the lighting environment and the computer monitor that was used for analysis and, therefore, could account for possible inaccuracies in recorded duration times.

TABLE V. COMPARISON OF CHANGING ELECTRIC FIELD PARAMETERS FOR POSITIVE STROKES

\begin{tabular}{|c|c|c|c|}
\hline Parameter & Studies & Samples & $\mathbf{A M}$ \\
\hline \multirow{3}{*}{ Peak instensities $(\mathrm{V} / \mathrm{m})$} & This study & 3 & 40.5 \\
\hline & $\begin{array}{c}\text { Schumann, et al. } \\
{[4]}\end{array}$ & 66 & 17.0 \\
\hline & Cooray, et al. [10] & 46 & 11.5 \\
\hline \multirow{5}{*}{ Rise time $(0-100 \%, \mu s)$} & This study & 3 & 23.7 \\
\hline & $\begin{array}{c}\text { Schumann, et al. } \\
{[4]}\end{array}$ & 72 & 9.5 \\
\hline & Hojo, et al. [11] & 32 & 22.3 \\
\hline & Cooray [12] & 20 & 8.9 \\
\hline & Ushio, et al. [13] & 19 & 18.0 \\
\hline \multirow{4}{*}{ Rise time $(10-90 \%, \mu \mathrm{s})$} & This work & 3 & 7.8 \\
\hline & $\begin{array}{c}\text { Schumann, et al. } \\
{[4]}\end{array}$ & 72 & 5.7 \\
\hline & Hojo, et al. [11] & 32 & 6.7 \\
\hline & Cooray [12] & 15 & 6.2 \\
\hline
\end{tabular}

TABLE VI. RECORDED CONTINUING CURRENT DURATIONS FROM LUMINOSITY PERSISTENCE IN HIGH-SPEED VIDEO FOOTAGE

\begin{tabular}{|ccccccc|}
\hline Polarity & Samples & $\begin{array}{c}\text { Duration } \\
\text { AM }\end{array}$ & $\begin{array}{c}\text { Duration } \\
\text { GM }\end{array}$ & Max & Min & Units \\
\hline Negative & 34 & 21.4 & 6.3 & 271 & 1 & $\mathrm{~ms}$ \\
Positive & 3 & 348.7 & 81.5 & 567 & 2 & $\mathrm{~ms}$ \\
\hline
\end{tabular}

\section{Notable points}

Throughout this study, certain constraints existed due to the equipment used and the data acquisition methodology. These, along with other noteworthy observations, are presented below:

- The peak changing E-field intensities could only be normalised if there was corresponding SALDN coordinate data on the strike-point locations of the recorded flashes.

- The changing E-field stroke data that could be correlated to the videos was limited to flashes with strike-points in the field of view of the cameras (illustrated in Fig. 3).

- The beginning stages of the electric field collapse are observable before $\mathrm{T}_{0}$. This information, if studied further, could have significant practical applications, 
such as improving the response time of certain lightning protection systems.

- An advantage of using both changing E-field measurements in collaboration with high-speed videos is that if unfamiliar anomalies occur in the electric field, the videos can be used to provide clarity. The converse also applies.

- A disadvantage of using both analysis techniques is that the field of view of the cameras is the limiting factor in the number of strokes that can be correlated to the changing E-field data. The antenna sensors register more flashes than the high-speed cameras can capture.

- The localised enhancement of the vertical electric field on the building that the antenna was placed has been noted. An enhancement factor is yet to be developed and as such, the presented electric field peaks are assumed to be marginally higher than the true values.

\section{CONCLUSION}

Presented in this paper are the results obtained from analysing the data obtained from 18 separate lightning flashes over Johannesburg, South Africa. A flat-plate antenna with an integrator was used to record the peak intensity, rise times and pulse duration parameters of the propagated vertical electric field from lightning flashes. The normalised peak intensities for the 34 recorded negative strokes and 3 positive strokes were $8.0 \mathrm{~V} / \mathrm{m}$ and $36.7 \mathrm{~V} / \mathrm{m}$, respectively. The pulse durations for the negative and positive stroke samples were $6.4 \mu \mathrm{s}$ and $33.4 \mu \mathrm{s}$, respectively. From highspeed video recordings of the corresponding flashes, the negative and positive strokes presented an average continuing current duration of $6.3 \mathrm{~ms}$ and $81.5 \mathrm{~ms}$, respectively.

\section{ACKNOWLEDGEMENTS}

The authors would like to thank the South African Weather Service (SAWS) for their support and for providing the SALDN data used in this paper. They would also like to thank Eskom for the support of the Lightning/EMC Research Group through the TESP programme. Thanks are extended to the Department of Trade and Industry (DTI) for THRIP funding as well as to the National Research Fund (NRF) for direct funding of the Research Group.

\section{REFERENCES}

[1] H. Pichler, G. Diendorfer and M. Mair. "Some Parameters of Correlated and Radiated Field Pulses from Lightning to the Gaisberg Tower" IEEJ Transactions on Electrical and Electronic Engineering, 2010 .

[2] A. Nag, V. A. Rakow, D. Tsalikis, J. S. Howard, C. J. Biagi, J. D. Hill, M. A. Uman and D. M. Jordan. "Characteristics of the initial rising portion of near and far lightning return stroke electric field waveforms" ICLP, 2010.

[3] M. N. Hamzah, M. Z. A. Ab Kadir, C. Gomes and S. N. M. Arshad. "Unusually Long Duration Lightning Electric Field Return Strokes in Malaysia” ICLP, 2014.

[4] C. Schumann, M. M. F. Saba, R. B. G. Da Silva and W. Schulz. "Electric fields changes produced by positive cloud-to-ground lightning flashes" Journal of Atmospheric and Solar-Terrestrial Physics, Volume 92, 2012.

[5] V. Cooray. An Introduction to Lightning. Springer Netherlands, 1st ed., 2015.

[6] S. N. M. Arshad, M. Z. A. Ab Kadir, M. Izadi, M. N. Hamzah, C. Gomes and J. Jasni. "Characterization of Measured Lightning Electric Fields Observed in Malaysia” ICLP, 2014.

[7] M. A. Haddad, V. A. Rakov, S. A. Cummer. "New measurements of lightning electric fields in Florida: Waveform characteristics, interaction with the ionosphere, and peak current estimates" Journal of Geophysical Research, Volume 117, 2012.

[8] A. D. Watt. "ELF Electric Fields From Thunderstorms" Journal of Research of the National Bureau of Standards, Volume 64D, 1960.

[9] M. D. Tran and V. A. Rakov. "A study of the ground-attachment process in natural lightning with emphasis on its breakthrough phase" Scientific Reports, 2017.

[10] V. Cooray, M. Fernando, C. Gomes, and T. Sorenssen. "The fine structure of positive lightning return-stroke radiation fields" IEEE Transactions on Electromagnetic Compatibility, Volume 46 (1), pp. 87-95, 2004.

[11] J. Hojo, M. Ishii, T. Kawamura, F. Suzuki and R. Funayama. "The fine structure in the field change produced by positve ground strokes" Journal of Geophysical Research, Volume 90, pp. 6139-6143, 1985.

[12] V. Cooray. "A novel method to identify the radiation fields produced by positive return strokes and their submicrosecond structure" Journal of Geophysical Research 91 (D7), pp. 7907-7911, 1986.

[13] T. Ushio, Z. Kawasaki, K. Matsu-ura and D. Wang. "Electric fields of initial breakdown in positive ground flash" American Geophysical Union. Paper no. 97d01975-0148-0227/97/97JD-01975, 1998. 